\title{
Do fazer poético da infância: 'uma coisa que não é a mesma coisa mas é igual'
}

\author{
Childhood poetics: 'a thing that is not the same thing but the same'
}

\author{
Violante F. MAGalhães \\ Centro de Investigação João de Deus da Escola Superior de Educação João de Deus, Lisboa, Portugal
}

-

Resumo: O reconhecimento de textos poéticos produzidos por crianças tem o mérito didático de trazer um incentivo para uma educação estético-literária. Quando publicadas, tais produções não só constituem um campo de fruição para o leitor (criança, jovem e adulto), como potenciam o campo formativo e possibilitam a investigação. Um dos projetos que, em Portugal, tem persistido na divulgação da escrita poética infantil é Cancioneiro Infanto-juvenil para a Língua Portuguesa, do Instituto Piaget. Iniciado em 1989 e idealizado para 30 anos, deste projeto resultaram já 17 volumes. Neste artigo, analisam-se os textos inseridos em alguns desses volumes, de crianças com idades compreendidas entre os 2 e os 6 anos. Se mais não fosse, analisados de forma entrecruzada com aspetos pedagógicos, científicos e didáticos, os textos em análise são depoimentos preciosos, pois são modos de as crianças se dizerem e ajudam-nos, a nós, adultos, a pensá-las, a conhecê-las melhor.

Palavras-chave: Literatura infantil; Escrita infantil; Cancioneiro Infanto-juvenil para a Língua Portuguesa

\begin{abstract}
The recognition of poetic texts produced by children has the didactic merit of bringing an incentive for aesthetic-literary education. When published, such productions not only constitute a field of enjoyment for the reader (child, youth and adult), but also enhance the field of education and enable research. One of the projects in Portugal that has persisted in the dissemination of poetic texts written by children is Cancioneiro Infantojuvenil para a Língua Portuguesa, of Instituto Piaget. Started in 1989 and designed for 30 years, it was already published 17 books. In this article, we analyze texts 'written' by children from 2 to 6 years of age. Moreover, analyzed in a way interspersed with pedagogical, scientific and didactic aspects, these texts are precious testimonies, because they are ways for children to express their own world and to help us, adults, to think about them, and to know them better.

Keywords: Children's literature; Children's writing; Cancioneiro Infanto-juvenil para a Lingua Portuguesa
\end{abstract}

In memoriam de Conceição Costa ${ }^{1}$

As crianças enlouquecem em coisas de poesia. Escutai um instante como ficam presas no alto desse grito, como a eternidade as acolhe enquanto gritam e gritam. ${ }^{2}$

\footnotetext{
1 Conceição Costa, que nos deixou em 2016, foi uma das mais entusiastas divulgadoras do projeto Cancioneiro Infanto-juvenil para a Língua Portuguesa, do Instituto Piaget, de cujos volumes são retirados os textos analisados neste artigo.

2 Extrato de "São claras as crianças como candeias sem vento", in Helder (1996).
} 


\section{O conceito de Literatura Infantil e a 'escrita' poética das crianças}

Enquadram-se no conceito de literatura infantil os textos ficcionais que escritores adultos criam para um destinatário extratextual particular, as crianças, atendendo às especificidades deste público; os que se revelam passíveis de serem lidos de forma acessível por crianças (por exemplo, textos da literatura de expressão oral); os textos provenientes quer do património oral quer da tradição culta que, embora não havendo sido escritos propositadamente para elas, foram antologiados, selecionados e adaptados com esse fim. Há também quem inclua na designação de literatura infantil as obras que tomam a infância como tema, bem como aquelas que são da autoria das crianças (cf. MAGALHÃES, 2009, p. 125-131).

Uma obra de arte contém rigor técnico, estética, mensagem, apelação. Esse rigor, esse trabalho artístico implicam um domínio aprofundado e hábil da língua - o material de que são feitos os textos literários. Visto que as crianças se encontram numa fase de aquisição da linguagem, considero que é difícil qualificar como literatura os textos escritos ou ditos (e registados por um adulto, que lhes 'empresta' a mão) por elas. Todavia, no inusitado do olhar revelado nesses textos não podemos deixar de reconhecer singularidades poéticas e discursivas. As próprias características da infância (os modos de pensar, agir e dizer) coincidem, muitas vezes, com procedimentos retóricos usados na literatura, em particular na poesia.

Em Portugal, ficou a dever-se a Alice Gomes, escritora e ensaísta de literatura portuguesa para a infância, a primeira recolha de textos feitos por crianças, que a autora veio a publicar em 1966, no volume Poesia da infância. Três anos depois, Maria Rosa Colaço, igualmente autora de literatura infantil, fazia sair $A$ criança e a vida, uma compilação de textos, narrativos e em verso, escritos por crianças. Em 1973, apresentando textos de crianças e respetiva reflexão sobre eles, Maria Alberta Menéres, reconhecida escritora de literatura infantil, publicou O poeta faz-se aos dez anos. Progressivamente, esse tipo de publicações foi-se avolumando, em evidente "reconhecimento de um papel interventivo à infância, não já como consumidora, mas como criadora de produtos culturais" (MAGALHÃES, 2009, p. 131).

No presente, quer em suporte papel quer em suporte digital, há publicações de cariz circunscrito (de uma determinada classe/ turma/ escola, de um agrupamento de escolas); multiplicam-se obras que resultam da cooperação de crianças, a título individual ou em grupo, com um ou mais escritores; há edições resultantes de concursos pontuais e outras enquadradas em projetos vários.
Ocupar-me-ei aqui de um projeto específico: o Cancioneiro Infantojuvenil para a Língua Portuguesa, do Instituto Piaget. Iniciado em 1989 e idealizado para 30 anos, deste projeto saiu, logo em 1990, um volume contendo os textos selecionados do primeiro concurso poético então feito. Os motivos que levaram à criação do projeto, bem como os objetivos delineados - entre eles, a reflexão sobre a emergência da razão imaginante e poética - são expostos nas "Notas introdutórias" que acompanham aquele livro de 1990 e os demais 16 publicados até ao momento. Este conjunto é produto dos sete concursos entretanto realizados. Tais concursos são abertos à participação de crianças e jovens oriundos de países onde se fala a Língua Oficial Portuguesa e a seus migrantes $^{3}$. No caso das crianças, são abarcados dois grupos de idades (até aos 6 anos e dos 7 aos 11 anos).

Optei por analisar sete volumes - correspondentes aos diferentes concursos poéticos - e por tomar como referência os textos do Grupo I, de crianças com 2 a 6 anos de idade. Cada um dos 17 volumes vindos a lume tomou por título um verso de um dos textos de crianças pequenas; designá-los-ei a todos pela sigla CI, acrescido da respetiva data. Em todos estes livros, creio, encontramos uma excelente oportunidade para escutar a voz das crianças.

\section{A escrita infantil no Cancioneiro Infanto-juvenil para a Língua Portuguesa}

As idades dos 2 aos 6 anos correspondem ao estádio de desenvolvimento cognitivo que Jean Piaget classificou como Pré-Operatório. Entre os processos cognitivos deste estádio "estão a função simbólica, a compreensão das identidades, a compreensão da causa e efeito, a capacidade para classificar e a compreensão do número" (PAPALIA, OLDS e FELDMAN, 2001, p. 312). Eles fazem parte do quotidiano das crianças e são, como procurarei provar, o alimento de qualquer dos volumes do Cancioneiro Infanto-juvenil para a Língua Portuguesa, do Instituto Piaget.

Com efeito, um a um, os textos do grupo etário dos 2 aos 6 anos que encontramos nos livros resultantes deste projeto reportam todas aquelas características, sem que ocorram diferenças significativas em cerca de 25 anos de existência do concurso. Estes volumes são, por consequência, um magnífico documento/testemunho em prol dessa verificação, como tentarei demonstrar nos exemplos abaixo.

Gil, de 4 anos, a pretexto de "O aniversário", procura descobrir a significação dos números. Por isso diz: "Mãe,

São também aceites a concurso poemas de adultos que versem sobre a infância ou a juventude. 
nenhum menino tem menos de um ano, porque não aparece o zero anos. Porque antes do 1 é o zero" (CI, 2010, p.33). Vislumbramos, deste modo, como "são as ações de reunir e ordenar que criam as condições do número, porque criam as condições das inferências e das deduções" (CHALON-BLANC, 2008, p. 67).

Quanto à compreensão da identidade, um outro menino, Marcos Tiago, no 'alto' dos seus 3 anos, esclarece-nos: "Eu estou aqui/ Em cima do meu pescoço" (CI, 1992, p. 13). O 'eu' tem existência, porque tem cabeça; curiosamente, ao ser definido o todo pela parte, acabou por ser gerada uma sinédoque. A definição do 'eu' associada à cabeça (continente) e ao pensamento/ ideia (conteúdo) é reiterada noutros volumes. Assim, diznos o João Filipe (4 anos): "Eu descubro tudo na minha ideia!" (CI, 1996, p. 69); hiperbolicamente, especifica o Paulo André (5 anos): "Penso com os pensamentos. Os pensamentos vão-se misturando por toda a cabeça" (CI, 1992, p. 13, sublinhado meu).

A identidade pode ainda surgir por identificação com o outro, espelhando como as crianças classificam/ agrupam objetos, acontecimentos, pessoas, baseadas em categorias de similaridades (e diferenças). Eis como esta menina de 4 anos, a Ana Margarida, reage quando a chamam de flor:

$$
\begin{aligned}
& \text { - Flor! } \\
& \text { - Eu não sou flor! } \\
& \text { - Porquê? } \\
& \text { - Porque se eu fosse flor } \\
& \text { tu também eras! } \\
& \text { (CI, 1992, p. 25) }
\end{aligned}
$$

Nestas idades, o pensamento mágico resulta de algumas características mentais que, a par e passo, são reveladas nestes textos. Centrada num mundo de pensamento próprio, a criança é incapaz de sair de si mesma. Exemplo acabado de egocentrismo é o de Luís Filipe que, com 2 anos, não imagina a categoria 'mãe' fora dele: "A mãe é minha" (CI, 2000, p. 14). Estoutro, o Telmo, de 3 anos, justifica do seguinte modo os atributos do pai: "O pai é bonito porque é meu pai" (CI, 2000, p.24). Já a Maria (5 anos), manifestando a sua simpatia, oferece-nos um texto que procura a rima, a comparação, não deixando, contudo, de erigir-se como termo da comparação feita: "Gosto muito de ti / como sim / como de mim" (CI, 2000, p. 71).

Em relação às pessoas que lhes são próximas como em relação a tudo o mais, as crianças fazem prevalecer os seus pontos de vista. Duas meninas, a Mariana e a Maria Raquel, de 4 e 6 anos respetivamente, consideram: "A Primavera é divertida porque ela vem sempre para onde eu vou" (CI, 2010, p. 89) e "Quando a música entra no meu corpo eu danço" (CI, 2010, p.26). Invertendo tudo para a própria experiência, deixam vir ao de cima a incapacidade de se colocarem na posição de outrem. Isso é também visível neste texto da Beatriz (3 anos), que justapõe acontecimentos, deixando evidenciar um domínio temporal incipiente: "Eu não me lembro de ser pequenina... Quando vocês eram pequeninos, quem é que tomava conta de mim?" (CI, 2000, p. 17).

Essas características mesclam-se com uma constante "tendência para atribuir vida a objetos inanimados" (PAPALIA, OLDS e FELDMAN, 2001, p.317). O animismo, recurso estilístico tão comum na literatura, é, no caso das crianças pequenas, aplicado a tudo o que saibam nomear, como veremos nos exemplos seguintes.

$\mathrm{Na}$ verdade, as casas, como os afetos, têm residência própria. A Sheila, de 3 anos, informa: "A minha casa mora ali” (CI, 2000, p. 33); o Pedro, igualmente com 3 anos, diz que "Os beijinhos vivem nas bochechas" (CI, 2014, p. 57). Acrescente-se que os beijos parecem ser facilmente 'transportáveis', como nos é mostrado pela curiosa dádiva de um outro menino, o Pedro, de 3 anos: "Trouxe-te um beijo... no bolso" (CI, 1990, p. 7).

Deixados abrigos físicos (habitação) e sobretudo simbólicos (manifestados nos beijinhos afetuosos), vejamos o que se passa com um outro abrigo, mais mundano - o do vestuário. A roupa tem vida própria, como parece esclarecer a Matilde, de 2 anos: "O meu bibe fala porque tem nome" (CI, 2014, p. 13). As árvores vestem-se (ou não), consoante as estações do ano - e estas últimas têm direito a estatuto socioeconómico. É o que inferimos da observação feita pela Leonor (3 anos): "O Outono é pobre... as árvores não têm roupa!” (CI, 2010, p.23). Até um par de sapatos pode ser personificado, revelando-se senhor de gostos próprios - não por acaso iguais aos de quem os calça..., presumimos que o Hugo, de 5 anos, que pormenorizadamente nos informa:

\footnotetext{
Os meus sapatos são bonitos

E eles gostam muito de andar

Quando eu vou para casa

Eles ficam muito contentes

Porque é para casa

Que eles gostam mais de ir:

Na rua têm frio

E em casa está quentinho!

(CI, 1992, p. 50)
}

O funcionamento do corpo também acontece por vontade própria, pelo que, para a Raquel, de 3 anos, "O chichi não sai porque ainda está a dormir!" (CI, 2000, p. 21) e para a Sara, de 5 anos, "A lágrima tem que chorar" (CI, 2014, p. 13).

Enfim, a confluência de capacidades físicas, determinação, ânimo, atribuída a objetos inanimados é tal, que chega a ser a 'coisa', seja ela qual for, que sente 
o humano (e não o inverso). É o que revelam os textos acima citados e o que poderíamos sintetizar nesta observação do Duarte (5 anos): "O vento empurra as coisas. O vento não se vê, sopra. O vento sente as pessoas" (CI, 2008, p. 36).

Aliás, e atendendo ao último exemplo, saliente-se que no conjunto destes volumes se evidencia uma proximidade tal das crianças com a natureza, um deslumbre imenso pela ordem do mundo, em tudo similares ao que encontramos em muita da poesia. Assim, se para a Bárbara, de 3 anos, "A lua quando está de dia vai ver outras cidades" (CI, 2014, p. 41), segundo a Rita, de 4 anos, ao aparecer, "A lua segue sempre o carro do meu pai” (CI, 2014, p.98). Por sua vez, o André (5 anos) constata que "Quando o sol dorme,/ As estrelas brincam" (CI, 1990, p. 20) e a Vera (4 anos) defende que "O vento bate as asas, quando chega a Primavera" (CI, 1990, p. 12).

Quanto à causa-efeito (que alguns dos exemplos atrás expostos tão bem ilustram), na fase dos persistentes 'porquês', as crianças ligam tudo com tudo, o que origina textos nos quais encontramos uma busca incessante de respostas. Conclui a Ana Margarida (4 anos): "Os porquinhos nascem na barriga da porquinha... Mas eu não sei onde nasce a porquinha!" (CI, 1992, p. 22). Algumas outras conclusões surpreendem pelo inusitado, como sucede com esta do Pedro, de 5 anos: "Nós não somos aprendidos na barriga da mãe/ aprendemos na escola!" (CI, 1996, p. 127).

Antes dos 'porquês', para explicar o mundo que as rodeia, as crianças fundem animismo e artificialismo, como patente no texto dito por esta menina de 3 anos, a Sara:
A chuva cai
porque a chuva
é para os senhores
porem o cachecol
e o guarda-chuva.
As nuvens é que mandam
a chuva cair...
Elas fazem uma careta
e... chove.
(CI, 1990, p. 16)

Com o progressivo domínio da linguagem, as crianças reconstituem verbalmente o vivido. $\mathrm{O}$ registo escrito do que dizem permite que assistamos, calmamente, ao modo como elaboram o pensamento. Veja-se como a Daniela Margarida, a um mês de fazer 3 anos, parte de observações e associações (a água lava; o mar tem água; a água do mar banha a areia...), reflete sobre o que observou (a espuma do mar na areia) e conclui: "O mar não lava a areia, não, não, o mar está sujo de espuma" (CI, 1996, p. 15).
Nos textos das crianças muito pequenas, é comum encontrarmos justaposições, pois elas vão elencando acontecimentos, de forma descontextualizada. É o que verificamos no caso deste menino de 2 anos, o João Pedro:

\author{
No Inverno \\ Está a chover pequenino \\ Há nuvens... \\ Casacos, luvas. \\ A neve é fria. \\ (CI, 2010, p. 72)
}

Lemos estes textos e não podemos deixar de lhes reconhecer características poéticas, muito provavelmente devido à proximidade com o processo retórico de enumeração.

À tendência para nomear tudo o que é visto, para justapor e para associar, alia-se esta outra: um conceito é definido pela fusão de elementos que surgem em diversas situações. Deixo aqui como exemplo de sincretismo um texto da Madalena, uma menina de 4 anos:

\author{
Mãe é \\ dar beijinhos e abraços \\ despedir \\ e dar colo. \\ (CI, 1996, p. 79)
}

Também o modo como as crianças olham a realidade, materializando as fantasias, se evidencia nestes textos. Por vezes, referem objetos/ações quotidianas, justificando-os com a fantasia. É deste modo que uma simples gema de ovo pode ganhar um fulgor inesperado, como comprovamos na afirmação do Bruno, de 4 anos: "Gosto de comer o Sol do Ovo" (CI, 1996, p. 93). Outras vezes, refreiam a fantasia, aplicando uma inesperada dose de realismo. Isso acontece nesta história da Ana (4 anos): "E a galinha vermelha estava muito velhinha, muito velhinha!... Se calhar, ela não usava cremes!" (CI, 1992, p. 39). Acontece também no reconto feito pelo Pedro Tomás ( 3 anos): "O lobo mau queria comer o Capuchinho Vermelho porque ela cheirava à sopa da mãe, que estava no cesto" (CI, 2010, p. 27).

Além disso, vão dizendo frases que, fruto da descontextualização e dado o inesperado das imagens, provocam um efeito poético. Na verdade, a "capacidade de armazenamento de imagens" (SPRINTHALL e SPRINTHALL, 2000, p. 106) própria de crianças nestas idades, acompanhada de uma outra notável capacidade - a de compreender e usar palavras para representar a realidade, fazem emergir textos metafóricos como este da Íris, de 2 anos: "O Outono é mar de folhas...!" (CI, 2010, p. 23). Ou estes outros dois de crianças de 4 anos, 
a Cláudia Inês e o Mauro, respetivamente: "As pedras são as estrelas do chão" (CI, 2000, p. 67); "As pessoas são sementes que crescem e não precisam de vento para mexerem" (CI, 2014, p. 76).

Por vezes, à metáfora associam-se sinestesias. Um festival de cores surge acoplado à visão, ao paladar, ao olfato. Vejamos: o Nuno Filipe (4 anos) explica que "As ervilhas são bolinhas verdes que andam na sopa" (CI, 1996, p. 60); a Sandra (4 anos) considera que "Morango é sabor encarnado" (CI, 1996, p. 61); a Áurea (2 anos) diz que "A árvore cheira a verde" (CI, 2014, p. 19). Num texto criado coletivamente por crianças de 3 anos quase sentimos como "O veludo é assim para apalpar; é bom, é macio" (CI, 2000, p. 19) e, no que se refere à audição, o Duarte, de 5 anos, esclarece: "Os foguetes são trovões de festa" (CI, 2014, p. 128). Agrupando vários sentidos, o Filipe, de 4 anos, considera que "O Magusto é a festa de Carnaval... das castanhas" (CI, 1990, p. 11).

Pela intuição, as crianças "são capazes de livres associações, fantasias e significados únicos ilógicos" (SPRINTHALL e SPRINTHALL, 2000, p. 106). E inventam soluções para os problemas criados por outrem ou por elas próprias, fazem aprendizagens, brincam com as palavras, atribuindo-lhes significados novos. Vejamos como a Daniela Alice (5 anos) soluciona o problema de "Fazer as cores":

\author{
Ir ao mar buscar água. \\ Fazer azul. \\ Ir à terra e colher a erva. \\ Fazer o verde. \\ Ir a um animal, tirar o sangue. \\ Fazer o vermelho. \\ Fazer um lume, buscar a cinza. \\ Fazer cinzento. \\ (CI, 2000, p. 73 )
}

Mais: sugerem definições e tecem comentários de extrema sensibilidade, que nos deixam rendidos. Por exemplo, de uma beleza invulgar são estas duas frases, respetivamente do Tiago André e da Maria do Mar, ambos de 3 anos: "O escuro chama-se tempo" (CI, 1996, p. 19); "O barulho do silêncio é nada!" (CI, 2010, p.47). Os pequenos autores delas aglutinam o que não sabem, o desconhecido. No primeiro caso, o tempo, do qual as crianças têm vaga noção, e o escuro, amedrontador; no segundo, ao vazio do silêncio que as crianças não entendem é aposto um outro vazio ("o nada"), originando uma concreção. E nós, leitores adultos, recebemos estas quase Greguerías como sinónimos do indeterminado, do impreciso. Num outro pequeno texto, uma criança de 5 anos, a Cláudia Raquel, define o ato de sonhar desta forma: "É uma coisa que quando as pessoas estão acordadas passa pelos olhos!" (CI, 1996, p. 136). Gaston Bachelard, atrevo-me a sugeri-lo, apreciaria estoutro modo de dizer rêverie.

$\mathrm{O}$ incentivo feito a crianças pequenas para que construam textos (com sequente registo escrito, feito pelo adulto, do que elas digam) trará consigo uma indiscutível fruição linguística, pois as crianças têm nesses momentos a possibilidade de ampliarem o que tão bem sabem fazer: "deliciar-se a imitar sons e a experimentar dizer muitas palavras diferentes" (SPRINTHALL e SPRINTHALL, 2000, p. 106). E isto independentemente da precisão dessas palavras e criando neologismos. Verificamo-lo em diversíssimas curtas proposições que encontramos nos volumes do Cancioneiro Infantojuvenil para a Língua Portuguesa, como seja nas destas duas crianças de 4 anos: a do Gonçalo Bruno, "Este gelado até inverna as mãos" (CI, 2000, p. 45, sublinhado meu) e a da Maria Beatriz, "Não vou ter frio porque eu sou muito esquentadora" (CI, 2008, p. 27, sublinhado meu). Ou então, nesta proposição mais desenvolta, da Andreia ( 3 anos), ao falar-nos sobre "Os pinhões":

Eu nasci
da barriga
da minha mãe.
E os pinhões
nasceram
da mãe pinha,
e do pai.
- Olha o filho pinhinha.
(CI, 1992, p. 16, sublinhado meu)

A surpresa com que, no quotidiano infantil, as crianças olham uma nova experiência e a dizem com ritmo aproxima os textos produzidos por elas de mecanismos utilizados na escrita literária. Olhemos de modo mais demorado para este texto de um menino de 3 anos, o João:

Ontem fomos ao elétrico à Praia das Maçãs não tem maçãs!

Havia água, praia fomos ao rio que tem pedras.

Brincámos com os brinquedos.

Brincar é bebé, brincar é ir para a praia.

Gosto de brincar com baldes, e gosto de brincar com giz.

Gosto de brincar com a mãe.

Fomos p'ró elétrico, é grande.

Faz bum, bum...

Andava depressa,

fazia assim: tlim, tlim, para parar; fez assim: tlim, tlim, acabou.

(CI, 2000, p. 35) 
O espanto que, perante um acontecimento vivido pela primeira vez, é revelado pelo João é comovente. Testemunhemos como o pensamento dele se constrói. $\mathrm{O}$ acontecimento novo foi ter ido de elétrico à Praia das Maçãs. O que sucedeu na viagem de ida, o leitor nunca o saberá. Uma Praia das Maçãs que, paradoxalmente, "não tem maçãs!", passa a ser a primeira informação digna de partilha (e admiração). Sempre havia, para consolo, "água, praia". Desconcertando-o muito provavelmente, a praia, para além do mar, tinha um rio. Brincou com os baldes, mas como "brincar é bebé" - e ele já não é bebé (tem 3 anos...), vai justapondo os pensamentos, de modo a legitimar a brincadeira (brincar é também "ir para a praia"). Para justificar o seu desacordo/ incómodo com a expressão "brincar é bebé", eventualmente, para resolver um 'eu já sou crescido' que não é dito explicitamente, buscou ele uma assisada ação (inexistente, presumimos) de "brincar com o giz". Para o caso de o símbolo da escola (o giz) não resultar eficaz no convencimento (dele/ nosso), ressalva o pequeno autor que também brinca com um 'outro' que é adulto - a mãe. Depois desta meditação (afinal, sobre o crescimento, os atos esperados em cada idade), retoma o fio da meada, relatando o percurso de regresso "p'ró elétrico". João começa por caracterizar o elétrico pelo tamanho ("grande"), pela 'voz' forte (um onomatopeico "bum-bum"), pela velocidade ("andava depressa"). O próprio elétrico era ainda senhor de outra habilidade/voz: "fazia assim: tlim-tlim, para parar". E como "fez assim: tlim, tlim", parou. Ou seja, este dia novo e memorável "acabou" e com ele "acabou" o discurso.

Ficou-nos o registo (que um adulto em boa hora decidiu recolher) desse dia, e o texto de uma criança de 3 anos, no qual se incluem, do ponto de vista do conteúdo, o animismo e a justaposição característicos desta idade, mas também uma tentativa de descentração da criança face ao mundo, um trabalho sobre a reversibilidade, da qual resulta, implícita ou explicitamente, a identidade (cf. PIAGET e INHELDER, 1995, p.91). Do ponto de vista formal, para além das onomatopeias ("bum-bum", "tlim-tlim"), do símbolo (o giz), da(s) hipotipose(s) (o giz presentificado; eventualmente, a mãe), ficou-nos um texto que contém: a admiração ("não tem maçãs!"), a adjetivação ("é grande"), o uso de advérbio de modo ("andava depressa"); a variação de tempos verbais (uso do presente, do pretérito perfeito, do pretérito imperfeito, do infinitivo). Considerando o domínio linguístico de uma criança de 3 anos, é muito, mesmo muito.

Entre os 2 e os 6 anos, pode não ser fácil o incentivo à construção de textos longos. Aliás, algumas vezes, e com muita graça, como sucede no texto que se transcreve a seguir, da Cláudia Inês (4 anos), as crianças contornam bem esse exercício de alargamento do discurso:
A vida é...

Crescer e fazer anos crescer e fazer anos crescer e fazer anos é assim a vida! (CI, 2000, p. 44)

Mas incentivar a criança a dizer, a contar, valorizando o que ela diga, ajudá-la-á, por certo, a combater tendências para um registo linguístico holofrásico, a embrenharse em jogos de linguagem, a dar destreza ao discurso, consequentemente à criatividade - afinal, uma das razões primeiras do projeto Cancioneiro Infanto-juvenil para a Língua Portuguesa, do Instituto Piaget. Na verdade, não se trata de fazermos a apologia de uma escrita/ registo em quantidade. Mas, mais facilmente o prazer de brincar com a língua, os neologismos, a recriação de textos acontecem se for excedida uma frase.

Evidentemente, a observação anterior não se aplica a textos que, embora contendo tão só uma ou duas frases, são de uma subtileza extrema. Assim sucede em parte dos exemplos que fui transcrevendo ou neste que agora acrescento, do André, de 4 anos: "Choveu e a fogueira ardeu..." (CI, 1996, p. 55). Neste caso, a procura de rima originou uma interessantíssima construção. Supostamente, a fogueira apagou-se com a chuva; mas como, na gíria, quando algo se perde, se usa a expressão 'ardeu', o segundo verbo escolhido foi esse - verbo que, por sinal, é exactamente contrário ao que eventualmente sucedeu (apagou-se, deixou de arder), pelo que se gerou um oximoro. Observemos ainda este outro exemplo: uma tolice é definida pelo Carlos André, de 3 anos, do seguinte modo: "É dizer o que não se diz" (CI, 2010, p.32). Em regra, temos por princípio dizer às crianças "isso não se diz' ou, com significado idêntico, "não digas tolices". Surpreendentemente, esta criança aglutinou estes dois enunciados e, confrontada com a definição de 'tolice', gerou uma antítese. Vejamos, ainda e por último, este também curto e, quanto a mim, belíssimo exemplo, em que parece despontar o fascínio pela linguagem por parte da Maria Inês, de 5 anos:
Há folhas
nas árvores
são folhas
novas
novinhas em folha.
(CI, 1996, p. 137)

\section{Um espólio ao serviço de uma reflexão sobre infância e poesia}

Perto de completar os 30 anos de publicações, o Cancioneiro Infanto-Juvenil para a Língua Portuguesa, 
do Instituto Piaget, constitui um espólio potencialmente muito rico para que investigadores de diferentes áreas (Educação, Filosofia, Linguística, Literatura, Literatura infantil, Pedagogia, Psicologia...) sobre ele se debrucem e reflitam.

Com efeito, a existência de um espólio constituído por um número altamente representativo de produções ditas/escritas por milhares de crianças das mesmas idades, ao longo de diferentes anos e provenientes de diversas localidades, ao dispor de investigadores, é algo de singular e entusiasmante. Muitas hipóteses poderão ser exploradas. Por exemplo, que vocabulário é usado? Que imaginário subjaz aos interesses das crianças? Mudaram ou não tais vocabulário e imaginário? Naturalmente, muitas outras hipóteses de pesquisa se sucederão.

Certo é que, por ora, com os volumes publicados, ao nosso dispor, concluímos que vale a pena colher proposições da infância, verificar confluências, apurar como poesia e infância se mesclam, complementam e iluminam. E isso é bom e necessário, pois infância e poesia, ambas tão agradáveis, não são assuntos fáceis. Porque, como escreveu o poeta Herberto Helder, "As crianças são uma verdade impraticável"4; e porque, como disse uma criança, a Beatriz, de 4 anos, "Poesia é uma coisa que não é a mesma coisa mas é igual” (CI, 2000, p.43).

\section{Referências}

CANCIONEIRO INFANTO-JUVENIL PARA A LÍNGUA PORTUGUESA. 1ำ Concurso Poético. Eu moro na minha mãe (v. I). Lisboa: Instituto Piaget, 1990.
2ํ Concurso Poético. O sonho vem pela cabeça (v. IV/V). Lisboa: Instituto Piaget, 1992.

3ํ Concurso Poético. O livro é uma história com boca (v. VII/ VIII). Lisboa: Instituto Piaget, 1996.

4ํㅡㄹ Concurso Poético. Silêncio é o barulho baixinho (v. X/XI). Lisboa: Instituto Piaget, 2000.

5 Concurso Poético. A casa do sol é a cor azul (v. XIV). Lisboa: Instituto Piaget, 2008.

6o Concurso Poético. Amo de ti (v. XV). Lisboa: Instituto Piaget, 2010.

70 Concurso Poético. As pessoas são sementes que crescem (v. XVII). Lisboa: Instituto Piaget, 2014.

CHALON-BLANC, Annie. Inventar, contar e classificar: de Piaget aos debates. Lisboa: Instituto Piaget, 2008.

HELDER, Herberto. Poesia toda. Lisboa: Assírio \& Alvim, 1996.

MAGALHÃES, Violante F. Literatura infantil. In: Sobressalto e espanto - Narrativas sobre e para a infância no Neorrealismo Português. Lisboa: Campo da Comunicação, 2009. p. 125-155.

PAPALIA, Diane E.; OLDS, Sally Wendkos; FELDMAN, Ruth Duskin. O mundo da criança. Lisboa: Mc Graw Hill, 2001.

PIAGET, Jean; INHELDER, Bärbel. A psicologia da criança. Porto: ASA, 1995.

SPRINTHALL, Norman A.; SPRINTHALL, Richard C. Psicologia educacional. Lisboa: McGraw Hill, 2000.

4 Extrato de "Uma criança disse...", in Helder (1996).

Recebido: 13 de setembro de 2017 Aprovado: 02 de outubro de 2017 Contato: violantemagalhaes@aeiou.pt (Violante F. Magalhães) 